Environment Conservation Journal 14(1\&2)41-45, 2013

ISSN 0972-3099 (Print) 2278-5124 (Online)

Abstracted and Indexed

\title{
Acute effect of detergent on lipid alteration in freshwater gastropod Bellamya bengalensis (Lamarck)
}

\section{P. Raghava Kumari}

Received: 15.09.2012

Revised: 11.01.2013

Accepted: 19.02.2013

\begin{abstract}
The freshwater gastropod Bellamya bengalensis exposed to 69.18ppm concentration of detergent (Tide) on lipid content in the tissue of foot, mantle and digestive glands for 96 hours exposure. Compare to control group there was significant change in lipid contents from foot, mantle and digestive glands in detergent exposed groups. Total lipids in the digestive gland increased after 96 hrs of exposure to detergent (Tide). The percent change in lipid level is +13.87 . But in case of foot and mantle, decrease of lipids was observed at 96 hrs exposure. This may be due to increased lipid synthesis or probably to facilitate transfer of materials from the storage organ to other parts of the body.
\end{abstract}

Keywords Bellamya bengalensis, TIDE detergent, Lipid alteration, foot, mantle, digestive gland.

\section{Introduction}

Freshwater ecosystem particularly rivers are under increasing threat due to rapidly expanding population, subsequently waste effluents from industries, domestic and farms open directly into them leading to the pollution crisis. During the past few decades, rising trends of population explosion, development of modern technology, industrialization and dramatic increase in the production and consumption of large variety of new synthetic chemicals and there by high amount of pollutants released into aquatic environment. Water pollution is the biggest menace of urbanization, industrialization and modern agricultural practices. It leads to alteration in physical, chemical and biochemical properties of water bodies as well as that of the environment. Industrial and domestic effluents which account for the pollution that endangers the aquatic life contain various toxic substances. To combat these toxic effects and stress conditions organisms develop the necessary

\section{Author's Address}

P. Raghava Kumari, Lecturer in Zoology, S.K.R. College for Women, Rajahmundry, East Godavari Dist, A.P, Mobile: +91 E-mail: raghavapk@gmail.com potential by altering energy metabolism. This results in severe changes in the metabolic cycles involving the inter change of biochemical constituents of tissues. Higher concentrations of toxicant in aquatic environment cause adverse effect on aquatic organisms at cellular or molecular level and ultimately it leads to disorder in biochemical composition.There is paucity of information about the alteration of biochemical constituents in gastropods in relation to sub-lethal exposure to detergents. The detergent (Tide) induced lipid alterations were studied in a freshwater gastropod, Bellamya bengalensis. Lipid plays a vital role in the maintenance of the structural integrity and functional abilities of the cell towards metabolism. They not only serve as vital energy stores and crucial constituents of cellular and sub-cellular membranes but also play a regulating role as chemical messengers (Prosser, 1973). Lipids have been shown to be important storage materials in the digestive gland and gonads of molluscs and are known to accumulate before aestivation (Krishna Murthy, 1968) or hibernation (Giese, 1966). The lipids of archaegastropods consist mainly of sterols, fatty acids, phospholipids and glycolipids and 96\% of the steroid is in the form of cholesterol in the family Neritidae (Ando et al., 1979). Chaudhari and

All rights of reproduction in any form reserved 
Lomte (1990) reported the impact of pesticides on lipid content of foot, mantle and digestive gland of Bellamya (Viviparus) bengalensis. Mule and Lomte (1994) reported the cypermethrin toxicity to lipid metabolism in Thiara tuberculata. Jinyong Zhu et al. (2011) investigated the ultrastructural alterations and biochemical responses in the hepatopancreas of the freshwater snail Bellamya aeruginosa exposed to toxic cyanobacterium. Padmaja and Balaparameswara Rao (1994) investigated the effect of an organochlorine and three organophosphate pesticides on lipid content of the foot and mantle on the freshwater snail Bellamya dissimilis.

\section{Material and Methods}

The snails Bellamya bengalensis collected from river Godavari were acclimatized for two days to the laboratory conditions and fed prior to experimental study. The present experiment was designed to study the effect of detergent (Tide) on $B$. bengalensis on various tissue metabolites. The snails were exposed to sub lethal doses of toxicants for 96 hrs. The biochemical parameters analysed in control and treated tests were conducted for lipids in foot, mantle and digestive gland of $B$. bengalensis. Samples were dried with filter paper to avoid the outer water content. The wet weights of all the tissues were taken to the nearest milligram and they were immediately transferred to the hot air oven maintained at $90-100^{\circ} \mathrm{c}$. The samples were dried for 3 to 4 days for the complete removal of their water content. The dried material was powdered and used for analysis. Sulphophosphovanillin method of Barnes and Blackstock (1973) was followed to estimate the total lipids. 20mg dry tissue powder was homogenized with $5 \mathrm{ml}$ of chloroform: methanol mixture (2:1) and centrifuged at $3000 \mathrm{rpm}$ for $15 \mathrm{~min}$. The supernatant was taken for the estimation of total lipids. $1 \mathrm{ml}$ of supernatant was taken into a test tube and allowed it to dry to evaporate the solvent (chloroform: methanol). To the residue in the test tube, $0.5 \mathrm{ml}$ of concentrated sulphuric acid was added and the mixture was stirred well and kept in boiling water bath for 10 min. and allowed the sample to cool to the room temperature. $2.5 \mathrm{ml}$ of the phosphoric acid - vanillin reagent was added and thoroughly mixed and the test tubes were stoppered with cotton wool. Then they were incubated for $30 \mathrm{~min}$ at room temperature. The optical density was measured at $520 \mathrm{~nm}$ in a spectrophotometer. The values were calculated against cholesterol standard and represented as \% dry weight of tissue powder.

\section{Results and Discussion}

The changes in biochemical composition of Foot, mantle and digestive gland of freshwater gastropod, Bellamya bengalensis exposed to acute concentrations of detergent (Tide) was studied along with control animals. The data was supported by various statistical analysis and the standard deviation and standard error of the mean were calculated. Student't' test was used to find out significance. The level of significance was used in the present study $(\mathrm{P}<0.05, \mathrm{P}<0.01$, $\mathrm{P}<0.001)$.Total lipids in the digestive gland increased after 96 hrs of exposure to detergent (Tide). The percent change in lipid level is +13.87 . This may be due to increased lipid synthesis or probably to facilitate transfer of materials from the storage organ to other parts of the body. But in case of foot and mantle, decrease of lipids was observed at 96 hrs exposure. In the foot of control snail lipid value was $0.93 \mathrm{mg} / 100 \mathrm{mg}$. It was decreased after $96 \mathrm{hrs}, 0.753 \mathrm{mg} / 100 \mathrm{mg}$. The mantle of controlled snail showed $0.84 \mathrm{mg} / 100 \mathrm{mg}$ of lipid, but it was decreased after 96 hrs, 0.74 $\mathrm{mg} / 100 \mathrm{mg}$. These values are showed in table 1 figure 1. There was slightly increased lipid droplets observed in the cytoplasm of digestive gland cells in treated snails which could be explained by enhanced utilization of energetic reserves during the experimental period due to intoxication.

\section{Results and Discussion}

The changes in biochemical composition of Foot, mantle and digestive gland of freshwater gastropod, Bellamya bengalensis exposed to acute concentrations of detergent (Tide) was studied along with control animals. The data was supported by various statistical analysis and the standard deviation and standard error of the mean were calculated. Student ' $t$ ' test was used to find out significance. The level of significance was used in the present study $(\mathrm{P}<0.05, \mathrm{P}<0.01$, $\mathrm{P}<0.001$ ).Total lipids in the digestive gland 
increased after 96 hrs of exposure to detergent (Tide). The percent change in lipid level is +13.87 . This may be due to increased lipid synthesis or probably to facilitate transfer of materials from the storage organ to other parts of the body. But in case of foot and mantle, decrease of lipids was observed at 96 hrs exposure. In the foot of control snail lipid value was $0.93 \mathrm{mg} / 100 \mathrm{mg}$. It was decreased after 96 hrs, $0.753 \mathrm{mg} / 100 \mathrm{mg}$. The mantle of controlled snail showed $0.84 \mathrm{mg} / 100 \mathrm{mg}$ of lipid, but it was decreased after 96 hrs, 0.74 $\mathrm{mg} / 100 \mathrm{mg}$.

These values are showed in table 1 figure 1. There was slightly increased lipid droplets observed in the cytoplasm of digestive gland cells in treated snails which could be explained by enhanced utilization of energetic reserves during the experimental period due to intoxication.

Table 1: Total Lipid content in the Foot, Mantle and Digestive gland of $B$. bengalensis exposed to Detergent (Tide) (Mean \pm S.D; $\mathbf{n}=3$ )

\begin{tabular}{llcl}
\hline & $\mathbf{9 6}$ hrs. Control & $\mathbf{9 6}$ hrs. Treated & \% variation \\
\hline Foot & $0.93 \pm 0.0458$ & $0.753 \pm 0.125^{\mathrm{NS}}$ & -19.03 \\
Mantle & $0.84 \pm 0.12$ & $0.74 \pm 0.141^{\mathrm{NS}}$ & -11.90 \\
$\begin{array}{l}\text { Digestive } \\
\text { gland }\end{array}$ & $1.47 \pm 0.105$ & $1.674 \pm 0.106^{* * *}$ & 13.87 \\
\hline${ }^{*} \mathbf{p}<\mathbf{0 . 0 5}$ & ${ }^{* *} \mathbf{p}<\mathbf{0 . 0 1}$ & ${ }^{* * *} \mathbf{P}<\mathbf{0 . 0 0 1}$ & NS Not significant
\end{tabular}

Fig. 1

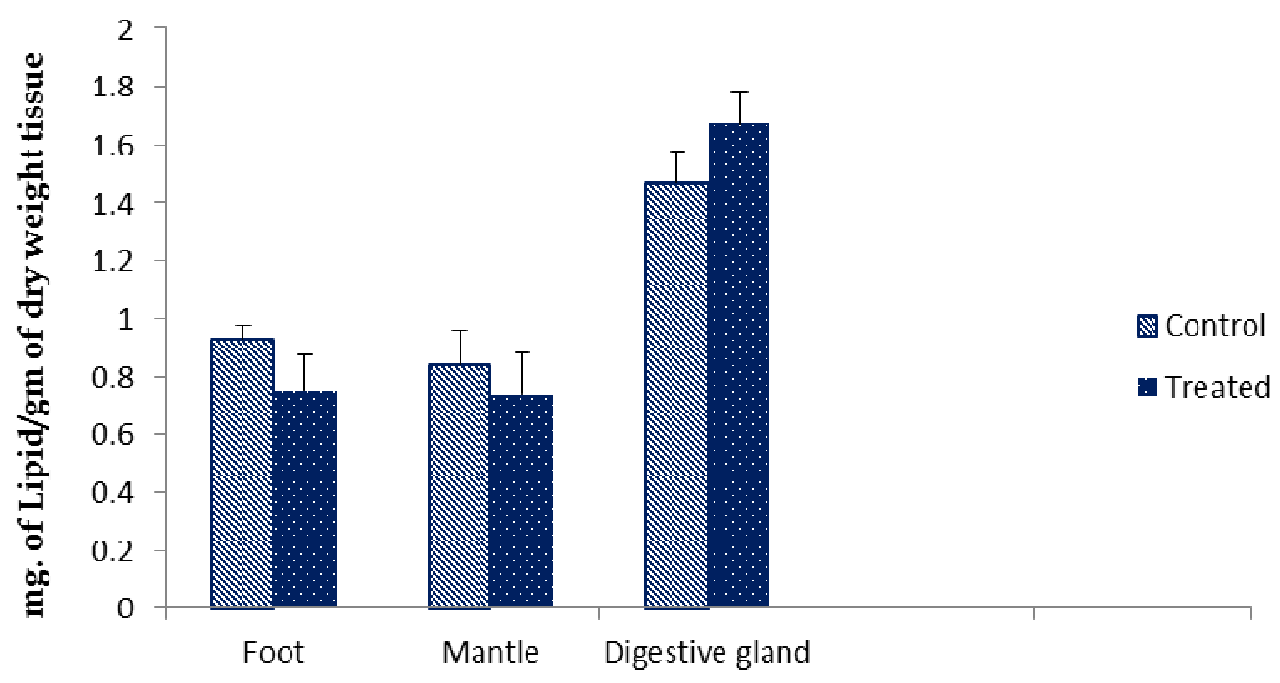

Higher concentrations of toxicant in aquatic the body gives important indication of stress. environment cause adverse effect on aquatic During stress an organism needs sufficient energy organism at cellular or molecular level and which is supplied from reserve materials i.e. ultimately it leads to disorder in biochemical carbohydrate, protein, lipid etc. Biochemical composition. The biochemical changes occurring in 
studies have been carried out at the level of whole animals, organs, tissues and sub cellular organelles. The lipid rich digestive gland (hepatopancreas) of gastropod molluscs is the key organ of metabolism and it is concerned with production of digestive enzymes, absorption of nutrients, endocytosis of food substances, food storage and excretion. It plays an important role in the synthesis of proteins and it should be noted that this is the first organ to face any foreign molecules that is carried through hepatic portal circulation and it is subjected to direct and serve damage. It has been found to be the major site of metal accumulation, and is the organ in which cellular alterations are most evident after exposure to organic and inorganic pollutants (Triebskorn et al., 1996). Vast literature is available on the toxicity of heavy metals, organopesticides, insecticides, hydrocarbon etc. in different aquatic animals related to effect on biochemical constituent levels in different tissues of animals. Lack of literature is available on the toxicity of detergents on molluscs which directly affects the biochemical constituents. Hence the present study was undertaken to evaluate the impact of detergent on carbohydrate, protein and lipid contents in different tissues of freshwater snail, Bellamya bengalensis. These results are in agreement with previous studies on snails and different organisms like crabs and fishes. In the present study, there was slightly increased lipid droplets observed in the cytoplasm of digestive gland cells in treated snails which could be explained by enhanced utilization of energetic reserves during the experimental period due to intoxication. The obtained results are in agreement with those reported by Mal Reddy and Venkateswara Rao (1987) who observed the increased activities of tri and diglyceride acylhydrolases and phospholipase and corresponding decrease in the glycerides and phospholipids in the snail, Lymnaea luteola exposed to copper. Auriemma and Battistella (2004) showed an increase of lipid vesicles both in digestive and basophilic cells was visible a week after the beginning of treatment with okadaic acid and derivatives in Mytilus galloprovincialis. The lipid content of foot and mantle was decreased after exposure period in the present snail B.bengalensis. Mule and Lomte (1992a) noted depletion in the lipid content of foot, mantle and digestive gland of Thiara tuberculata exposed to monocrotophos.
Klobucar et al. (1997) reported the reduction of lipid peroxidation in the digestive gland of a freshwater snail, Planorbarius corneus exposed to chronic and sub concentrations of pentachlorophenol. By the analysis of biochemical changes which are considered as sensitive indices of pollution damage, early warning signs of distress could be detected and they may also help in providing threshold toxicity concentrations for chronic exposure.

\section{Acknowledgement}

I am thankful to University Grants Commission for the sanction of scholarship under FDP Programme. Thanks are due to authorities of Andhra University for providing necessary facilities.

\section{References}

Ando, T., Kanazawa, A., Teshima, S. and Miyawski, 1979. Sterol components of coral reef molluscs. Mar. Biol, (Berlin) 50: 169-172.

Auriemma, R. and Battistella, S., 2004. Biochemical and histological alterations of Mytilus galloprovincialis digestive gland after exposure to okadaic acid and derivatives. ISJ 1: 66-71.

Barnes, H.Y. and Blackstock, J., 1973. Estimation of lipids in marine animals and tissues. Detailed investigation of sulphophosphovanillin method for total lipids. J. expt. Mar. Biol. Ecol, 12(10): 103-118.

Chaudhari, T.R. and Lomte, V.S., 1990. Impact of pesticides on lipid content of foot, mantle and digestive gland of Bellamya (Viviparus) bengalensis. Ind. J. Inv. Zool. Aqua. Biol, 2: 27-30.

Giese, A.C., 1966. Lipids in the economy of marine invertebrates. Physiol. Rev, 244-298.

Jinyong Zhu, Kaihong Lu, Chunjing Zhang, Jingjing Liang, and Zhiyong Hu., 2011. Biochemical and ultrastructural changes in the hepatopancreas of Bellamya aeruginosa (Gastropoda) fed with toxic cyanobacteria. The Scientific World Journal, 11: 2091-2105.

Klobucar, G.I.V., Lajtner, J. and Erben, R., 1997. Lipid peroxidation and histopathological changes in the digestive gland of a freshwater snail Planorbarius corneus L. (Gastropoda, Pulmonata) exposed to chronic and subchronic concentrations of PCP. Bull. Environ. Contam. Toxicol, 58: 128-134.

Krishna Murthy, R.V., 1968. Hepatopancreatic unsaturated fatty acids during aestivation of the snail Pila globosa. Comp. Biochem. Physiol, 24: 279-282. 
Mal Reddy, N. and Venkateswara Rao, P., 1987. Copper toxicity to the freshwater snail, Lymnaea luteola. Bull. Environ. Contam. Toxicol, 39: 50-55.

Mule, M.B and Lomte, V.S., 1992a. Monocos (Monocrotophos) induced alterations in lipid content of the snail Thiara tuberculata. J. Ecotoxicol. Environ. Monit, 2(2): 125-128.

Mule, M.B and Lomte, V.S., 1994. Cyperkill (Cypermethrin) toxicity to lipid metabolism in Thiara tuberculata. Proc. Environ. Biol, 3(2): 131-134.
Padmaja, R. J. and Balaparameswara, Rao, M. 1994. Effect of an organiochlorine and three organophosphate pesticides on glucose, glycogen, lipid and protein contents in tissue of the freshwater snail Bellamya dissimilis (Muller). Bulletin of environmental contamination and Toxicology, 53(1):142-148.HYPERLINK http://www.springerlink.com/content/?Author=J.+Padmaj $\underline{\mathrm{a}+\mathrm{Rambabu}}$

Prosser, C.L. 1973. Comparative animal physiology (Edt) C.L. Prosser W.B. Saunder Company Philadelphia/London/Toranto P. 79.

Triebskorn, R., Henderson, I.F., Martin, A. and Kohler, H.R., 1996. Slugs as target or non-target organisms for environmental chemicals, in: BCPC Symposium. Proceedings No. 66: Slug and Snail Pests in Agriculture. 